\title{
The Advantages of a Global Solvency Standard
}

\author{
Nikolaus von Bomhard \\ Munich Re, Königinstrasse 107, Munich, 80802, Germany.
}

Insurance and reinsurance companies provide their services and risk taking capacity not only in their home markets, but also in other territories and jurisdictions. Sophisticated supervisory approaches must exist to protect the policy-holders adequately in such a complex environment. It is thus not beneficial for supervisors, insurers and reinsurers as well as policy-holders if each territory establishes its own supervisory regime. Only a global supervisory approach can cope with the comprehensive requirements and would ensure that resources of all stakeholders are appropriately allocated. The paper compares the supervisory regimes in Europe and the Unites States, that is in the two main insurance markets. The analyses reveal that the future European standard Solvency II exhibits many features that would also be required for a potential future global solvency standard.

The Geneva Papers (2010) 35, 79-91. doi:10.1057/gpp.2009.31

Keywords: insurance regulation; Solvency II; economic valuation

\section{Introduction}

Global insurance and reinsurance companies provide their risk-taking capacity not only in their home markets but also in many other territories and jurisdictions. They currently operate in heterogeneous supervisory environments, characterised by a variety of quantitative and qualitative requirements for risk capital, risk management and disclosure. Despite the existence of mutual recognition of regulatory regimes which ease these burdens, there is a need for a global solvency standard. Its introduction would enable companies to reduce their resources in complying with regulatory reporting requirements; it would make local regulatory capital requirements comparable and thus further pave the way for a level playing field among insurers. Further integral steps towards a more homogeneous supervisory landscape would be a group solvency regulation approach, together with the introduction of a lead supervisor concept including the set-up of colleges of supervisors for insurance and reinsurance groups. Finally, all the issues mentioned represent benefits for the policy-holder in form of more attractive offers and conditions.

The financial crisis drew the world's attention not only to the banking sector but also to the insurance and reinsurance industry. A global supervisory system capable of detecting future dislocations of financial markets earlier or to mitigate the adverse impact of financial crisis situations is currently lacking. The regulatory landscape is fragmented and supervisors have preferred to elaborate country-specific solutions. Currently, policy-makers, supervisors, investors and other stakeholders seek a system which might be the role model for the future solvency standard. Europe, with its 
Solvency II approach, is well positioned in this respect, as it presents one of the most advanced supervisory frameworks both in terms of quantitative requirements (e.g. setting of the solvency capital requirements (SCRs) and principles for determining technical provisions) as well as qualitative prerequisites (e.g. duties and powers of supervisory authorities and requirements regarding companies' risk management systems).

Not only the industry and supervisors worldwide but also politicians are now advocating and demanding improvements in the supervisory landscape. The Group of Twenty (G-20), for example, stated in the light of the recent dislocations on the financial markets that " $[\ldots$... We will take action to build a stronger, more globally consistent, supervisory and regulatory framework for the future financial sector, which will support sustainable global growth and serve the needs of business and citizens".

The focus of this paper is not on the overall establishment of a level playing field in financial sector supervision but on changes in the insurance and reinsurance industry. Flamée and Windels ${ }^{2}$ among others have addressed the former topic, which is also being intensively discussed by insurance supervisors around the globe. Although there are certain similarities between the financial industries (e.g. banking, insurance and securities trading) which would justify the introduction of an integrated global approach, the differences are far from negligible. It therefore seems preferable to start with a common approach towards insurance regulation. The topic of this paper has already been dealt with to a certain extent by Elderfield. ${ }^{3}$ Thus, the main objective of this paper is to consider the latest developments and to raise additional points and concerns. The next section introduces current supervisory developments in the major global insurance and reinsurance markets. The subsequent section elaborates the advantages and requirements of a global supervisory standard, looks at the consequences of failing to introduce such a standard, and deals with the potential role of the International Association of Insurance Supervisors (IAIS). The last section provides a summing-up.

\section{Overview of current regulatory developments}

Comprehensive and far-reaching endeavours and initiatives are currently being pursued around the globe to modernise and enhance regulatory systems. Covering all the developments would go far beyond the scope of this paper, so the main focus will be on the European Union and the United States, which in terms of premium volume provide the major share of primary insurance and reinsurance capacity (over 70 per cent according to Munich Re estimates). Some other jurisdictions and their initiatives will be briefly mentioned nonetheless.

With the introduction of the Swiss Solvency Test, Switzerland has one of the most advanced supervisory approaches, which is risk based and exhibits strong elements of

\footnotetext{
${ }^{1}$ G-20 (2009)

${ }^{2}$ Flamée and Windels (2009)

${ }^{3}$ Elderfield (2009)
} 
group support. With regard to the acceptance of the Swiss supervisory approach, there is a memorandum of understanding (MoU) with the Committee of European Insurance and Occupational Pensions Supervisors (CEIOPS) stating that the Swiss Federal Office of Private Insurance (FOPI) may be appointed as lead or co-supervisor for cross-border supervision of insurance and reinsurance groups domiciled in Switzerland. ${ }^{4}$

The Bermuda Monetary Authority (BMA) continues to work on mutual regulatory recognition standards by developing a framework for group supervision, enhancing supervisory and public disclosure standards, and setting the standards for qualitative risk management reviews. The ambitious goal of implementing a group supervision framework is scheduled to be achieved by $2011 .^{5}$ Furthermore, BMA has established a roadmap to Solvency II equivalence and is actively preparing to cope with the requirements for the introduction of global insurance supervision. ${ }^{6}$

Regulators in Asian countries like Japan, Korea and Singapore, and also in Australia and Mexico, have already made or started to make changes to their regulatory frameworks. In particular, this involves the establishment of risk-based systems.

\section{Strengthening the European supervisory landscape: Solvency II}

The Solvency II project represents the ongoing efforts of the European Commission and various stakeholders to modernise the solvency regulation system for insurers and reinsurers in the European Union. Solvency II is designed to replace the current, simply structured European solvency regulations (Solvency I) with a modern, consistently risk-based system of financial supervision. This means moving away from a rules-based approach towards principles-based regulation in which companies' risks are evaluated using risk-adequate and market-consistent - that is economic - criteria. As a result, risks can be assessed more precisely and promptly. These features show that Solvency II is good for consumers, putting the protection of policy-holders at the centre.

The Solvency II Framework Directive (Level 1 in the Lamfalussy process) was finally agreed in May 2009 by the European Parliament and the Economic and Financial Affairs Council. The derivation of the Level 2 implementing measures, which is being prepared by the European Commission on the basis of advice provided by CEIOPS, is the next step towards successful implementation in $2012 .^{7}$ The industry and other stakeholders responded to the first and second wave of CEIOPS Consultation Papers in June and September, while the third wave is expected to be published in November, with responses due in December. Against the background of the financial crisis, it seems that CEIOPS is currently increasing the overall requirements and trying to introduce excessive prudence and conservatism into the Solvency II framework. These trends should not be accepted, as they contradict the initial spirit of the Level 1 framework directive. The industry must speak up now and

\footnotetext{
${ }^{4}$ IMF (2007)

5 BMA (2009)

${ }^{6}$ BMA (2008)

${ }^{7}$ Refer to www.ceiops.eu to follow the consultation and implementation process.
} 
raise its concerns in order to maintain the principles-based initial character, which seems to be in increasing danger of getting lost. If the direction that CEIOPS is advising is not changed, a solvency and supervisory system will emerge that places too great a financial and administrative burden on the industry and fails to fully encourage the right behaviour. As a result, consumers will be faced with a higher cost for insurance than might otherwise have been the case. This should sound the warning bells for European supervisors, as shaping Solvency II in this way might threaten the position of the insurance industry and the level playing field with other financial industries. Insurers should not be held responsible for developments in the financial crisis which they did not cause and which did not affect the insurance industry as much as it did others.

\section{The current state of the U.S. supervisory system and related modernisation initiatives}

Although the U.S. Federal Government maintains the constitutional authority to regulate the business of insurance and reinsurance, decades ago it delegated that authority to the 50 states. As a consequence, each state now exercises independent supervisory authority over the operations of companies that pursue insurance/ reinsurance business within the state. Companies licensed in all the states must comply with the licensing and regulatory requirements in all 50 jurisdictions. This system has been increasingly criticised by national and international insurance/reinsurance organisations as being inefficient and in need of modernisation. Many have called for a more uniform, national approach to regulation. Currently, each supervisor participates as a member in the National Association of Insurance Commissioners (NAIC), a private organisation established in part to promote an appropriate degree of regulatory uniformity among the states. However, due to its private character, the NAIC lacks any legal authority to act as a national supervisor or to otherwise require the states to enact uniform regulatory standards.

Despite its lack of actual legal authority, the NAIC has played a leading role in designing, and encouraging the state supervisors to adopt, uniform solvency standards. At the centre of the quantitative standards is the Risk-Based Capital (RBC) Model, which was introduced by the NAIC in $1994 .{ }^{8}$ The model, which is generally uniform across states, provides a capital adequacy standard related to the main risks of insurers and requires insurers to set aside a safety capital buffer. Individual RBC models exist for life, health and property-casualty. The formulae focus on the main risk categories, meaning that it is not a comprehensive risk-based approach. Individual charges are factor based and result from multiplication of an underlying volume factor with the respective risk factor. The aggregation of the risk categories assumes that risk categories are either independent or fully dependent, which results in the simplest form of covariance approach. ${ }^{9}$ There is an incremental and targeted use of internal models (e.g. modelling of interest rates from fixed annuities, or a stochastic modelling approach for variable annuities with guaranteed

\footnotetext{
${ }^{8}$ Holzmüller (2009)

${ }^{9}$ Vaughan (2009)
} 
benefits). Safeguards like the parallel application of standard deterministic scenarios or the requirement that the resulting capital charge from the internal model should not be unreasonably low must be considered in these cases. Finally, the resulting risk capital amount is compared with the insurer's available capital resources to derive information on its financial strength, which is translated into several levels of supervisory intervention. ${ }^{8}$

The U.S. supervisory process also includes requirements for periodic on-site examinations by the competent regulator, offsite financial analysis based on data reported by the insurer, and independent audits. From 2010 onwards, an enhanced risk-focused examination approach is to be in place which targets such issues as risk management and risk governance. NAIC procedures for the coordination of multistate examinations have been developed and applied by the states, and other internal NAIC processes have been established for identifying and monitoring financially impaired insurers. Furthermore, insurers file their financial statements with the NAIC, and this information is made available to each state's supervisor. Regulatory disclosure comprises the above-mentioned requirement to file financial statements, which are stored on a central NAIC database. The information is used for benchmarking and peer-group comparisons. ${ }^{9}$

Notwithstanding the NAIC's considerable contributions to U.S. insurance solvency regulation, the recent financial crisis has prompted calls for further improvement of the U.S. system. In response, in June 2008, the NAIC announced a Solvency Modernization Initiative intended to investigate "[ ... ] new ideas and an opportunity to create the globally pre-eminent solvency system ... ". ${ }^{10}$ Areas focused on in this initiative include capital requirements, group supervision and reinsurance.

In addition to the NAIC's Solvency Modernization Initiative, the U.S. Treasury recommended in its 2008 Blueprint for a Modernised Financial Regulatory Structure the establishment of an optional federal charter (OFC) for insurers. ${ }^{11}$ The proposal advocates creating a system with responsibility for federal chartering, licensing, regulation and supervision for insurers, reinsurers and insurance producers (i.e. agents and brokers). The OFC would not be compulsory; insurers could still opt for the current state-based regulation instead of being regulated at the national level. States would not have jurisdiction over those electing to be federally regulated.

The NAIC itself has recently adopted a proposal for the modernisation of U.S. reinsurance regulation that has significant implications for both U.S. and international reinsurers. Under the NAIC proposal, reinsurers that are organised and licensed in qualified non-U.S. regulatory jurisdictions would be able to provide creditable reinsurance to U.S. insurers upon certification by a single U.S. "Port of Entry Supervisor". The non-U.S. reinsurer would be able to apply for certification by any U.S. state that had been approved by a federal agency (the "Reinsurance Supervision Review Board") as a qualified Port of Entry Supervisor. Similarly, U.S.-domiciled

\footnotetext{
${ }^{10}$ NAIC (2009)

11 U.S. Treasury (2008)
} 
reinsurers would be allowed to transact business throughout the U.S. pursuant to a license issued by a single "Home State Supervisor".

Like the U.S. Treasury's OFC proposal, the NAIC's reinsurance regulatory modernisation proposal would require federal statutory authorisation.

\section{A global supervisory approach}

\section{Advantages of a global supervisory approach}

Without doubt, a global approach to insurance supervision would have several advantages for supervisors, insurance and reinsurance companies and their policyholders. Many countries already have or are in the process of revising their regulatory systems to give them a more risk-based approach. These isolated endeavours, however, disregard an important point: increasing globalisation and internationally operating insurance and reinsurance companies with a wide-ranging network of branches and subsidiaries require a global supervisory standard.

Harmonisation of quantitative and qualitative regulatory standards is advantageous for all parties involved. The industry will benefit from the fact that only one standard has to be followed and resources do not need to be allocated so as to comply with numerous regulatory systems. This is of particular importance for companies which intend to expand into new markets abroad. The cost and resources issue should not be neglected on the regulatory side either. Having a uniform supervisory standard will save regulators money, as their staff can concentrate on one set of rules and requirements. Focusing on a single regime is also appealing in the light of regulatory standards and models that are becoming more complex and challenging, and which will require people with special skill-sets. The war for talent, that is the search for people with actuarial and risk management expertise, has already begun, and demand is still on the rise. Policy-holders and other intermediaries will also benefit from lower prices as a result of the emerging level playing field and thus increased competition between insurers and reinsurers and their lower spending for compliance with various supervisory frameworks. If policy-holders were to be asked, they would almost certainly advocate a globally consistent standard precisely for these reasons.

Transparency is another keyword in the current debate. Adherence to the same set of standards by companies worldwide minimises the risk of regulatory arbitrage. And a new standard geared towards the latest findings in the industry will avoid inefficiencies going forward.

Globally operating insurance and reinsurance companies play an important role in the development of national economies by assuming and disseminating risks and making entrepreneurial decisions. These activities, however, harbour the risk of spreading economic instability, which could be mitigated by having a global regulatory regime. Having such a regime would enable developed countries to demonstrate more effectively the existence of efficient and stable insurance markets against the background of the current volatile financial markets and a looming worldwide recession scenario. Supervisors will be better prepared for the occurrence of future crisis situations (e.g. the increasing probability of pandemics, the rising severity of natural catastrophes and terrorism alerts, to mention just a few). 


\section{Features of a future global solvency standard}

Any developments towards a global supervisory standard have only a low prospect of success if they do not include the United States and the European Union, the world's two largest insurance and reinsurance markets. This section examines various factors that are potentially beneficial and important for a global solvency standard and looks at how the supervisory regimes in the U.S. and EU are currently dealing with them. This overview does not claim to be exhaustive, but it singles out some of the important factors.

\section{Risk-based approach}

The new standard should derive a $\mathrm{RBC}$ requirement that takes into account all the risks to which companies are specifically exposed. In the calculation of the SCR, Solvency II considers all the major risk categories (i.e. non-life, life and health underwriting risk, ${ }^{12}$ market risk, credit risk and operational risk) which are regarded as having a potential impact on the company and can be quantified. Either a standard formula or an internal model is used to evaluate the impact of these risk categories. The aggregation process in the standard formula takes into account dependencies between subclasses of each risk category, but also considers dependencies between the risk categories at the top aggregation level utilising a covariance approach. The internal model might employ more complex methods to capture potential dependencies like tail correlations or copulas. The U.S. RBC model consists of different factor-based models for life, health and non-life insurers. The non-life formula, for example, covers asset risk, underwriting risk (although catastrophe risk is not considered in the model), credit risk and business risk, which includes operational risk. Dependencies between individual risk classes are considered only at the top aggregation level, assuming either full dependency or independency. The current form of the U.S. RBC model cannot be classified as fully risk-based, as it does not cover all the major risks to which companies might be exposed.

\section{Economic approach}

An economic approach is characterised by showing all assets and liabilities evaluated at their present or fair values. This eliminates all hidden reserves and smoothing elements, and shows the economic equity capital as a true reflection of the company's financial situation. Under Solvency II, companies are required to prepare an economic balance sheet. Impacts are especially observable on the liabilities side, where technical provisions have to be determined based on a market-consistent approach. This means that in their economic balance sheet, insurance companies need to show a risk margin on top of the discounted best estimate. The risk margin should ensure that the company, if in difficulties or a state of insolvency, can attract a third party which assumes the portfolio. The risk margin serves as a rate of return that the assuming company receives on the risk capital, which it would have to set aside. The U.S. RBC

\footnotetext{
${ }^{12}$ Underwriting risk covers premium and reserve risk.
} 
approach uses information shown in the statutory annual statement based on accounting rules adopted by the NAIC. For the time being, this cannot be considered an economic approach. However, a 2007 NAIC issues paper explicitly deals with the topic of fair value measurement, smoothing the way for the application of economic principles. Moreover, parallel work on accounting standards undertaken by the International Accounting Standards Board and Financial Accounting Standards Board also aims at the introduction of economic and fair value principles in international accounting.

\section{Internal models}

The admissibility of internal (risk) models, which are considered better suited to capture complex risk situations, is another feature that a future global solvency standard should offer. Under Solvency II, companies will have the choice to use internal model approaches for all or part of their risks. The use of internal models is safeguarded by a comprehensive approval process. Model governance means that six tests, most notably the use test, have to be passed before permission is granted for dayto-day application. By contrast, the NAIC sees the introduction of internal models as a means to model risks in cases where standard approaches deliver inferior results. The consideration of internal models to capture the total risk situation of U.S. insurers is, however, not an intention or objective of the regulator. The NAIC is rather cautious and conservative in permitting the use of internal models. This is evident in the safeguards which have been built into the introduction of internal models and in the fact that internal models tend to increase the capital requirement compared with the factor-based approach. ${ }^{9}$

\section{Calibration standards}

Supervisory models achieve a higher degree of transparency and appeal if the calibration of the model allows users to evaluate or benchmark the level of prudence assumed against other models (e.g. rating agency approaches). For the standard formula and internal models, Solvency II uses a common risk tolerance (1-in-200-year event) and a uniform risk measure (Value at Risk) for all risk categories. The time period over which risks are evaluated is one year, and the approach assumes a goingconcern situation. The U.S. RBC formula is not calibrated towards a specific level of confidence, whereas the admitted internal model components are generally calibrated using the Tail Value at Risk as the risk measure.

\section{Principles-based approach}

The financial market crisis has shown the advantages of a principles-based, economic and risk-based regulatory framework for the stability of the financial industry. Principles-based regulation will raise a number of challenges for insurance companies and supervisors alike. Insurers will face more uncertainties, as the principles-based approach will leave more scope for interpretation as regards to the comprehensive requirements with which the companies have to comply. Senior management will have the final responsibility for ensuring that the company is working towards the 
regulatory objectives. In contrast to the situation with rules-based regulatory approaches, simply complying with specific pre-defined requirements will no longer suffice. Functions like risk management, internal audit and compliance will gain in importance. Under a principles-based approach, supervisors will have more rights but also more duties. Owing to the degree of freedom in regulation, they will need to have a very good understanding of companies' approaches and they will have to deal with complex issues going forward (e.g. the approval process for internal capital models). Furthermore, they will have the flexibility but also the burden of deciding on the degree of materiality and proportionality that companies have to consider with respect to their regulatory compliance requirements. A "one size fits all" method will no longer exist. The future Solvency II standard due to be implemented in 2012 will be principles-based. However, the current Level 2 process and the specification of the implementing measures contain indications that regulators are tending towards some degree of rules-based supervision, which should be avoided and challenged by the industry and other stakeholders now. The U.S. approach can be characterised as rulesbased $^{8}$, but trends towards a more principles-based treatment are observable.

\section{Risk governance}

The Solvency II approach towards risk governance stresses the ultimate responsibility of senior management for all risk management activities. Companies are encouraged to set up functions for risk management, compliance, internal audit and actuarial operations to facilitate proper risk governance processes. In addition to quantitative safeguards, the introduction of these measures is seen as a further means to mitigate and control the vulnerability of companies to adverse events on the insurance and capital markets. In this process, own risk and solvency assessment (ORSA) has been conceived as a tool that requires insurance and reinsurance undertakings to properly assess their own short- and long-term risks and the amount of own funds necessary to cover them. The current approach in the United States does not have an equivalent to the ORSA approach. There are no explicit requirements to produce a document with an internal assessment of the risks, details of the risk management system or the risk profile of the company for submission to the regulator.

\section{Group supervision}

A necessary feature of a global solvency standard would be the availability of group supervision - with the group supervisor coming from the country where the company is domiciled. Solvency II has adopted this idea, and the intention is to choose the lead supervisor from the country where the parent company is registered. Supervisors from the states where the group has subsidiaries and branches will make up a "college of supervisors". This group shall make amicable decisions concerning group solvency issues. One disappointment for groups is the rejection of the group support regime, which would have allowed groups to derive more advantage from the diversification benefits resulting from the selected structure of branches and subsidiaries operating in various jurisdictions. However, the concept will be re-evaluated three years after the inception of Solvency II. The NAIC has developed the lead state supervisor concept for groups, under which a state or states can be chosen to act as "lead" for various 
group solvency oversight work. However, there is no group solvency assessment in place, nor any concept for recognising risk diversification benefits or capital mobility within the group.

\section{Collateral requirements}

A truly global supervisory approach should not require any collateral requirements, as these severely impede the efficient flow and allocation of capital. Nonetheless, various forms of such requirements continue to exist and are a constant source of irritation. Regulators also recognise the need to alter current practice and the NAIC's latest draft proposals represent an encouraging move in this direction. Non-U.S. reinsurers must currently prove that they have established 100 per cent collateral on U.S. risks with a U.S. bank. The revised NAIC framework proposes relaxing this practise. The NAIC would allocate one of five ratings to non-U.S. reinsurers. At the top end of the scale, rating class one would mean that no collateral would be required; at the other end (rating class five) 100 per cent collateral would have to be provided, as at present. This seems to be a step towards a more risk-based and economic approach. Solvency II is scheduled to approve reinsurance risk mitigation by companies which comply with the requirements and are not in breach of the SCR without any collateral requirements.

\section{Summary}

A comparison of the U.S. regulation and the future Solvency II approach in the European Union shows that the latter is currently more suited to meeting the requirements of a future global solvency standard which provides the benefits outlined earlier in this section. In the United States, although several developments and initiatives point in the right direction, the supervisory approach presented by the NAIC does not fulfil all the demands of such a framework. Some of the issues not addressed, however, have already been targeted for further study in the NAIC's Solvency Modernisation Initiative.

\section{Potential downsides from the pursuit of individual solutions}

The failure to implement a global supervisory standard could have adverse impacts in increasingly integrated and interlinked insurance markets. The remainder of this subsection lists some of the most obvious points. The pursuit of stand-alone developments would inevitably create uneven regulatory playing fields. Fair competition is scarcely achievable in a situation of inadequate regulatory equivalence. This applies to various levels and stages in the regulatory process.

Different risk capital requirements for the same risk and the same amount of exposure are an adverse development, impeding fair competition and presenting a disadvantage for policy-holders. The same is true in respect of the admissibility criteria for own funds or available capital resources, which impact the capital mix of companies and the resulting return-on-capital requirements.

Diverse levels of supervisory requirements for risk management and for supervisory reporting and disclosure result in an uneven distribution of costs and resources. This 
favours companies acting under supervisory standards with relatively low requirements, while creating drawbacks for companies operating under more advanced regimes with more comprehensive requirements.

Lastly, the absence of group supervision creates severe disadvantages for globally operating insurance and reinsurance groups. Insurance groups would not be considered in terms of their capacity to efficiently employ capital and exploit regional diversification benefits. Rather, groups have to capitalise each entity according to the respective local regulatory capital requirements. Furthermore, groups cannot utilise the advantages of a lead supervisor who cooperates with a college of supervisors, but have to deal with each supervisory authority separately. Such a procedure leads to higher costs and inefficient utilisation of resources.

\section{IAIS as global insurance supervisory authority}

The previous sections have shown that the creation of a global supervisory standard for insurance is an ambitious but worthwhile undertaking. Apart from the availability of the regulatory standards and the readiness of the insurance and reinsurance companies, there remains the question of whether or not a regulatory authority with sufficient and adequate competencies and powers exists to ensure compliance with global standards.

The IAIS, which represents insurance regulators and supervisors worldwide, appears to be the best-suited candidate. The organisation was set up in 1994, and its main objective is the release of Insurance Core Principles (ICPs), other principles and regulatory standards. The ICPs present fundamental principles for proper regulation and deal, for example, with the supervisory system, prudential requirements or questions relating to the ongoing supervisory process. The ICPs have been accepted by IAIS members as an appropriate supervisory standard, but in practice companies must still comply with the local regulatory standards and requirements. IAIS Principles, Standards and Guidance Papers are currently non-binding, that is they are not directly applicable to (re)insurers but have to be implemented by IAIS members.

While there seems to be general agreement among stakeholders that the IAIS needs to be strengthened in order to achieve a global solvency standard in the mid to long term, there is still uncertainty about how exactly this could be accomplished. One option would be to restructure the IAIS into a WTO-like organisation with the power to issue binding guidelines and conduct appropriate dispute settlement procedures. It is also conceivable that the OECD Insurance Committee might play a more prominent role. Both options could be explored in more detail.

Many believe, though, that the most promising idea for insurance is to adopt a process similar to the one developed for the Basel Committee on Banking Supervision. The Basel Committee was established by the central bank governors of the G-10 countries in 1974. Interestingly, the Committee does not possess any formal supranational supervisory authority. Its conclusions do not, and were never intended to, have legal force. Like the IAIS, the Basel Committee formulates supervisory standards, guidelines and best practices. But usually banking supervisory rules are endorsed by the central bank governors and heads of banking supervision of the G-10 
countries, as was the case with the Basel Accord 1988, Basel II in 2004 or the Revised Framework in 2006.

Without prejudice to the first two options and without going into the pros and cons of the different options, this last approach seems to be the most workable one, as it might be implemented within a reasonable period of time.

\section{Conclusion and outlook}

It has become evident that international approaches towards common insurance regulation are an important undertaking. Policy-makers and supervisors should therefore not miss the opportunity now to raise the issue of a global standard for the supervision and regulation of the insurance and reinsurance business. Promising developments are especially observable in Europe, with the scheduled implementation of the Solvency II regime by late 2012 and to a lesser degree also in the United States. Supervisors in several countries have shown their interest in Solvency II features and some have launched the implementation of similar requirements to ensure mutual recognition of the supervisory regimes (e.g. Bermuda). A new global approach must definitely involve the two main markets, the United States and the European Union. Only then can the current undertakings evolve into global efforts to adopt a worldwide supervisory standard in which insurance and reinsurance companies are subject to similar supervisory conditions and requirements, no matter where they come from or where they intend to do business. The objective must be to revise the current supervisory landscape, which is uneven and impedes the functioning of globally operating insurers' and reinsurers' business models. The resultant lack of a level playing field for regulation results in higher costs and inefficiencies for (re)-insurers, supervisors and policy-holders alike. The IAIS, which has been working for several years on standards and principles for a new global supervisory framework, might be a good starting point for a new and effective supervisory authority.

\section{References}

Bermuda Monetary Authority (BMA) (2008) 'Building Resources to meet Advances in Global Insurance Supervision', from www.bma.bm/document-centre/consultation-papers/insurance.asp.

Bermuda Monetary Authority (BMA) (2009) 'Implementing Group-wide Supervision', from www.bma.bm/ document-centre/consultation-papers/insurance.asp.

Elderfield, M. (2009) 'Solvency II: Setting the pace for regulatory change', The Geneva Papers on Risk and Insurance-Issues and Practice 34(1): 35-41.

Flamée, M. and Windels, P. (2009) 'Restructuring financial sector supervision: Creating a level playing field', The Geneva Papers on Risk and Insurance-Issues and Practice 34(1): 9-23.

Group of Twenty (2009) 'The Global Plan for Recovery and Reform', London, from www.g20.org/ Documents/final-communique.pdf, accessed 2 April 2009.

Holzmüller, I. (2009) 'U.S. RBC standards, Solvency II and the Swiss solvency test', The Geneva Papers on Risk and Insurance Issues - and Practice 34(1): 56-77.

International Monetary Fund (IMF) (2007) 'Switzerland: Financial Sector Assessment Program-Factual Update-Insurance Sector Market and Regulatory Developments', from www.imf.org/external/pubs/ft/ scr $/ 2007 / \mathrm{cr}-07203 . p d f$. 
National Association of Insurance Commissioners (2009) 'NAIC Solvency Activities Review', State Government Representative Webinar, from www.naic.org/documents/committees_e_solvency_presentation .pdf, accessed 4 June 2009 .

U.S. Treasury (2008) 'Blueprint for a Modernized Financial Regulatory Structure', from www.treas.gov/ press/releases/reports/Blueprint.pdf.

Vaughan, T.M. (2009) 'The Implication of Solvency II for U.S. Insurance Regulation', Policy Brief Networks Financial Institute, Indiana State University, from www.naic.org/Releases/2009_docs/ 090305_vaughan_presentation.pdf.

\section{About the Author}

Nikolaus von Bomhard was born in Gunzenhausen in 1956. He completed his law studies at the universities of Munich and Regensburg with a doctorate. He joined the Munich Re graduate trainee programme in 1985, and afterwards worked as an underwriter in the Operational Division: Fire/Treaty. In 1992 he was appointed Deputy Head of the Operational Division: Germany. In $1997 \mathrm{Mr}$ von Bomhard took on the task of building up and managing the Munich Re office in Saõ Paulo, Brazil. In 2000 he was appointed to the Board of Management and from 2001 was responsible for the Europe 2/Latin America Division. He was appointed Chairman of the Board of Management with effect from 1 January 2004. Mr von Bomhard is responsible for Group Development, Group Investments, Group Communications, Group Audit, Group Executive Affairs. He is married with two children. 